\title{
Reasoning as a source of justification
}

\author{
Magdalena Balcerak Jackson • \\ Brendan Balcerak Jackson
}

Published online: 1 March 2013

(C) Springer Science+Business Media Dordrecht 2013

\begin{abstract}
In this essay we argue that reasoning can sometimes generate epistemic justification, rather than merely transmitting justification that the subject already possesses to new beliefs. We also suggest a way to account for it in terms of the relationship between epistemic normative requirements, justification and cognitive capacities.
\end{abstract}

Keywords Reasoning - Inference - Justification · Normative requirements · Cognitive capacities

\section{Introduction}

In this essay we examine three cases in which a subject arrives at a certain belief on the basis of a process of reasoning. In each case the subject's belief is intuitively epistemically justified. And yet in each case, it is not plausible that the belief inherits all of its justification from that of any prior beliefs or other mental states involved in the reasoning; or so we will argue. If this is correct then we must recognize that reasoning can sometimes generate epistemic justification, rather than merely transmitting justification that a subject already possesses to new beliefs. We should include reasoning in the list of mental states and processes, such as perception and justification, that function as sources of justification. This is a rather surprising conclusion. We suggest a way to account for it, and for the cases themselves, in terms of the relationship between epistemic normative requirements, justification and cognitive capacities.

\footnotetext{
M. Balcerak Jackson $(\bowtie) \cdot$ B. Balcerak Jackson University of Cologne, Cologne, Germany

e-mail: mbalcerakjackson@me.com

B. Balcerak Jackson

e-mail: bbalcerakjackson@gmail.com
} 
In Sect. 2 we present each of the three cases, and in each case motivate the diagnosis that the reasoning involved generates (rather than merely transmits) justification. The discussion of each case inevitably involves substantive claims about how particular beliefs, and particular sorts of transitions among beliefs, are epistemically justified. Such claims are bound to be controversial, of course, and along the way we consider some challenges that are likely to arise. But our argument is meant to be cumulative: while there may not be many epistemologists who would be prepared to accept our diagnosis of all of the cases we discuss, certain extremely plausible commitments in epistemology should lead one to accept our diagnosis of one or another of them. The conclusion that reasoning is a source of justification thus appears to be a "side effect" of various other attractive epistemological commitments. In Sect. 3, we develop a positive account of the cases. According to the account we offer, the sort of reasoning involved in the cases is subject to a kind of epistemic appraisal that is determined by the normative requirements relating beliefs and other attitudes. These normative requirements are grounded in specific cognitive capacities or competences of the subject.

Before introducing the cases, we need to say a bit about how we will be using talk of epistemic justification, and about what we mean by calling something a process of reasoning. For our purposes, to say that a subject has justification to judge or believe that $p$ is to say that it is (or would be) epistemically appropriate for her to believe that $p$; she is (or would be) doing what she ought to, epistemically speaking, in forming or maintaining that belief. A subject has justification to believe that $p$, when she does, in virtue of being in some state; we will refer to this as the state that justifies her in believing that $p$, or as her justification for the belief. ${ }^{1}$ A subject can be in some state that justifies her in judging that $p$-that makes it epistemically appropriate for her to believe that $p$-even though she does not, in fact, hold the belief. So let us say that a subject has a justified belief that $p$ just in case (a) she believes that $p$; (b) she has justification for believing that $p$; and (c) her belief is based on her justification for believing that $p$. There are notorious difficulties saying precisely what it is for a belief to be (epistemically) based on some state or process. For our purposes, however, we can rely on the rough and intuitive suggestion that a subject's belief is based on some state or process when it is her ground for the belief, the reason for which she believes it. ${ }^{2}$ It should be uncontroversial that the reasoning processes we describe in the following sections can provide epistemic bases for justified beliefs, and that they do so in the cases under consideration.

Our main contention is that reasoning can generate justification; but what counts as reasoning? We have no general account to offer here. John Broome suggests that every case of reasoning is "a sequence of mental states that have propositions as their contents." 3 One feature that distinguishes clear cases of reasoning is that there

\footnotetext{
1 Here "state" should be construed very broadly to include occurrent experiences, extended processes that the subject undergoes, and perhaps much else. Note that we make no assumption here that the state in virtue of which the subject has justification must be a purely internal state, or a state to which the subject has conscious access. Thus we are not presupposing a picture of justification that is internalist in either of these senses.

2 Our use of terminology here basically follows Pryor (2005a).

3 Broome (2001). Note that Broome clearly does not intend this to be a sufficient condition for reasoning.
} 
is an apparent content gap between the content of the first mental state in the sequence and the content of the mental state that is its ultimate conclusion. For example, suppose that a subject notices that his keys are not in his coat pocket, and concludes that he left them on his desk at work. The subject's two beliefs in this case have two very different contents: that his keys are not in his pocket, on the one hand, and that he left them on the desk at work on the other. One can easily imagine different ways the subject might "cross" that gap in an epistemically appropriate way: by remembering that he emptied his pockets onto the desk when he arrived at work, and then later left the office in a rush, for example, or by reflecting on his habit of always keeping his keys either in his pocket or on his desk. These are paradigmatic processes of reasoning. ${ }^{4}$ Compare this case with a case in which one visually perceives a red circle and endorses this perception in belief, straightaway forming a belief that there is a red circle. There is no content gap to cross here, and it is at best a degenerate case of reasoning. ${ }^{5}$

But not every sequence of mental states that exhibits a content gap counts as a case of reasoning: think of a subject drifting from thought to thought in an episode of daydreaming. A second feature that characterizes paradigmatic cases of reasoning is that it is intuitively appropriate to subject the transitions among the steps of the thinker's reasoning, and the thinker himself, to certain sorts of epistemic normative evaluation. When the subject reasons, I always keep my keys either in my coat pocket or on my desk; they're not in my pocket; so I must have left them on my desk, we judge the steps to be ones that the subject ought to take, or that it is good to take, from an epistemological point of view. We might praise him, or say that he has conducted himself as he should, epistemologically speaking, in so reasoning. These sorts of appraisals are appropriate for us to make in this case. Likewise, had he taken some other steps-they're not in my pocket, so they're probably not on my desk either-it would be appropriate for us to judge them to be epistemically bad or impermissible, and to say that he has not conducted himself as he should. This contrasts with the daydreamer, for whom such normative evaluation seems out of place. We certainly can criticize his transitions, as he drifts idly from thought to thought, but doing so is like criticizing someone who is simply walking down the street for his poor performance of a ballet routine. ${ }^{6}$

Merely noting these two features as hallmarks of paradigm cases of reasoning falls short of offering a full account. But the presence of these features in the cases to follow is at least very good grounds for classifying them as genuine cases of reasoning. And in any case, the claim we defend here- that there are cases in which

\footnotetext{
${ }^{4}$ We do not build it into the notion of reasoning that it is always fully conscious, or always involves a deliberate sequence of transitions among mental states. Reasoning can be automatic and largely nonconscious. But for those who prefer a more restricted notion of reasoning, the cases to be discussed below can be construed as fully conscious and deliberate.

5 According to Boghossian (2003, pp. 235-236) content gaps are symptomatic of cases of inferential justification. When the gap between the content of the premise state and the content of the conclusion state is too large, we have to regard the conclusion state as inferentially justified. Correlatively, most would not count the belief that there is a red circle as inferentially justified in this case.

6 The analogy may suggest that it is constitutive of epistemically evaluable reasoning that it is something the subject engages in intentionally. However, this is not something we assume.
} 
a series of epistemically appropriate transitions in thought can, by itself, generate grounds for belief - is interesting enough, whether or not we choose to call them cases of reasoning, strictly speaking.

\section{The cases}

One paradigm case of reasoning is when a subject engages in a deliberate process of logical deduction. The following is such a case:

Case 1: Fozzy logic. Fozzy has no evidence one way or the other concerning the question of whether there are any talking green creatures. But he temporarily adopts the assumption that Kermit is a talking green creature. Working under this assumption, Fozzy thinks to himself: in this case there would be at least one thing-namely, Kermit-who is a talking green creature. Discharging his assumption, Fozzy draws the (material) conditional conclusion that if Kermit is a talking green creature, then there is at least one talking green creature. He goes off in search of Kermit to check his color and language skills.

In this case Fozzy forms his belief on the basis of the reasoning described; the reasoning functions as his ground, the reason for which he judges that if Kermit is a talking green creature, then there is at least one talking green creature. In a case like this, under ordinary circumstances, we would surely grant that the belief Fozzy ends up with is justified.

What is the source of Fozzy's justification? In usual cases of beliefs arrived at by logical deduction, belief in the conclusion is typically taken to inherit whatever justification is had by the beliefs in the premises. In this case, however, there are no premises. Fozzy's deduction does not begin from justified beliefs of his, but rather from a hypothetical assumption for which he has no justification; it is a mere supposition "for the sake of argument". Each step that follows is then simply a matter of making transitions to which he is epistemically entitled: the transition from Kermit is a talking green creature to There is at least one talking green creature, and the transition from this bit of hypothetical reasoning to flat-out acceptance of the conditional. None of this requires Fozzy to draw on any other justified beliefs of his. To account for Fozzy's justification in this case, all we need to do is secure that he reasons competently, that the steps of his reasoning meet whatever the appropriate epistemic standards are for such reasoning. We do not need to identify other justified beliefs on which his justification for the conclusion somehow depends. If this is correct, however, then we ought to conclude that Fozzy's reasoning itself generates his justification for belief in the conclusion, rather than merely transmitting it.

One might object: surely Fozzy's reasoning will meet appropriate epistemic standards for conferring justification on his conclusion only if he has some justification for thinking that the transition from Kermit is a talking green creature to There is at least one talking green creature is a good one-for example, only if he has justification for believing that the rule of existential generalization (or this 
particular instance of it) is valid. If this is so, then Fozzy already has sufficient justification for believing the conclusion; there is no need to see it as generating any new justification, rather than simply as helping to ground his belief in the justification he already has.

This objection cannot solely concern Fozzy's application of existential generalization; if it did, we could simply re-describe the case as involving some other, more basic deductive transition to which the objector's requirement of prior justification doesn't apply_an instance of conjunction reduction, perhaps. So the objection must be that one is never entitled to make a deductive transition in the absence of prior justification for thinking that the transition is good. However, there are familiar considerations that speak against imposing such a strong demand on deductive reasoning. Lewis Carroll-type regress worries seem to show that we cannot require the subject always to include the premise that his other premises entail the conclusion in his reasoning; if so then the subject will never actually be able to license the transition from premise to conclusion. ${ }^{7}$ Nor do we seem able to require that the subject always have justification for thinking that the transition is good, since it is unclear how he could ever acquire the required justification without being able to employ deduction at the outset. ${ }^{8}$ The upshot of these considerations is that there must be at least some basic deductive steps in reasoning that are what Paul Boghossian calls blind transitions: transitions that we are epistemically entitled to make without the need for prior, independent justification for believing that we are entitled to do so. For any given blind deductive transition $\mathrm{T}$, there is a modification of the Fozzy scenario above in which a process of reasoning that incorporates $\mathrm{T}$ generates justification in the way indicated.

Another sort of objection focuses on the transition from Fozzy's hypothetical reasoning to his flat-out belief in the conditional conclusion. Even if there must be some blind deductive transitions, why think this is one of them? And if it is not, then doesn't the justification that Fozzy has for making this step transfer to the conclusion?

Suppose that this transition is not blind. ${ }^{9}$ Still, this does not suffice to fully account for Fozzy's justification for his conclusion. Imagine that Fozzy explicitly knows that the rule of conditional proof is valid. This is not enough to make it appropriate for him to believe that if Kermit is a talking green creature then there is at least one talking green creature. In order to be justified in believing this particular conditional, he needs something further, linking this antecedent and that consequent. This something further is provided by the hypothetical reasoning that establishes the consequent, on the assumption of the antecedent. But as we have seen, the goodness of this reasoning does not depend on him having prior justification. The conclusion, again, is that Fozzy's reasoning itself contributes justification for the conclusion he reaches on its basis.

\footnotetext{
7 See, of course, Carroll (1895).

8 Boghossian (2003) forcefully presses this sort of worry.

9 There is some ground for insisting that the transition is blind. After all, it is intuitively closely connected to one's grasp of the material conditional that one is prepared to judge If $P$ then $Q$ when one judges $Q$ by reasoning from the hypothetical assumption of $P$.
} 
Another type of reasoning, familiar to philosophers and practically irreplaceable as a method for testing philosophical hypotheses, is the consideration of thought experiments. Here is an example:

Case 2: the Chinese Room. Scooter sits in the philosophy seminar room, and (at the prompting of his instructor) imagines that John Searle is locked in a room and is given various batches of Chinese writing, along with English instructions for manipulating the Chinese symbols, in the ways Searle himself describes in his famous Chinese Room thought experiment. ${ }^{10}$ Entertaining the scenario as instructed, Scooter thinks to himself, Searle does not really understand Chinese at all. He then concludes that if Searle were in the Chinese Room, he would not really understand Chinese.

Intuitively, Scooter's conditional belief is justified. ${ }^{11}$ The reasoning is no doubt familiar: Scooter begins by forming a representation of the Chinese Room scenario in imagination, and thinking about what would be the case if that scenario obtained. ${ }^{12}$ On the basis of his consideration of the scenario, he judges that Searle does not really understand Chinese. ${ }^{13}$ This process of reflection then leads him to conclude that if Searle were in the Chinese Room, he would not understand Chinese. The conclusion is intuitively one that it is perfectly epistemically appropriate for Scooter to draw.

As before, we can ask: what accounts for Scooter's justification? As in the previous case, it does not appear to be inherited from the justification had by any beliefs employed in the reasoning; the reasoning does not appear to employ any beliefs. One might suggest that Scooter's judgment about the scenario is somehow based on a theory of what understanding amounts to, and how it relates to the syntactic manipulation of symbols. If so, then the justification Scooter has for that theory can transmit to, and hence account for, his belief in the conclusion. The problem with this suggestion is that the appropriateness of one's judgment about a thought experimental scenario cannot, in general, depend on already having explicit justified belief in a theory of the subject matter in question. If it did, then reflection on thought-experimental scenarios could not play the epistemic role that common philosophical practice assigns to them. Judgments like Scooter's about Searle's failure to understand Chinese can help him come to know what understanding is, and how it relates to the syntactic manipulation of symbols. If his judgment depended on already having justified belief in a theory, there would be no need for the thought experiment. This is one lesson from the paradox of analysis: if judgments about thought experiments can be informative-which they clearly can, and which a great deal of philosophical practice presupposes - then it cannot be that

\footnotetext{
${ }^{10}$ Searle (1980).

11 If necessary, of course, we can re-describe the case as one that involves a less controversial thought experiment, such as a Gettier-style scenario.

12 Scooter's representation need not be visual, nor need the propositions that characterize the scenario be represented in any other specific way.

13 Making a judgment under a hypothetical assumption is not, of course, a matter of forming a belief but of adding a new proposition to what is being supposed.
} 
they need to be underwritten by prior justification for believing a background theory. ${ }^{14}$ Some might want to insist that Scooter must have implicit or tacit knowledge of a theory of understanding. If tacit knowledge requires justification then this is no progress. But if, on the other hand, tacit knowledge does not require justification, then it does not help explain Scooter's justification in this case (unless perhaps it plays a role in the kind of explanation we sketch in Sect. 3).

An alternative reply is to grant that Scooter's justification is not inherited from other beliefs, but to insist that this is because his consideration of the thought experiment does not amount to a case of reasoning after all. On some views, imagining the scenario produces in the subject a conscious seeming state-an appearance that things are a certain way-and this seeming gives her immediate justification for believing that things are the way they seem. ${ }^{15}$ On such a view, it simply seems to Scooter that Searle in the Chinese Room does not understand Chinese, and this justifies the corresponding belief. The analogy here is with socalled dogmatist views of perceptual justification, according to which having a perceptual experience as of a red square provides the subject with immediate justification for believing that there is a red square in front of him. ${ }^{16}$ Scooter's belief is justified in much the same way, immediately rather than on the basis of reasoning.

However, the analogy with perception fails: the plausibility of dogmatism about perceptual judgments depends, at least in part, on the close connection between what is primarily given to the subject in visual experience and what she judges to be the case. One enjoys a visual experience with the content $p$, and this makes one prima facie justified in forming a belief with the same content-a belief that $p$. In other words, in this sort of case there is no content gap to bridge. In our case, however, there is a content gap. The content of Scooter's imaginative representation of the scenario concerns Searle sitting in a room manipulating Chinese symbols according to a manual; his judgment about the scenario has a different content that concerns Searle's ability to understand Chinese. This feature is a hallmark of paradigm cases of reasoning, and it is hard to see how to fit it into the perceptual story.

Notice, too, that we could describe a case in which Scooter is directly observing an actual Chinese Room scenario, rather than imagining one. He sees Searle receiving the bits of Chinese text, searching through the manual, and handing out different Chinese symbols. In this case it is absurd to think that Scooter is simply immediately justified in believing that Searle does not understand Chinese, in the same way he is justified in believing that, say, the room has blue walls. Rather, observation gives him information about Searle that helps him to infer that Searle does not understand Chinese. But it is implausible that the judgment would be inferential in this case and immediate in the imagination case.

\footnotetext{
14 The paradox of analysis, and the role of thought experiments in providing justification, are discussed in Balcerak Jackson (2012).

15 For an explicit commitment to the view that responses to thought experiments are immediately justifying seemings see Chudnoff (2011), or Bengson (manuscript).

16 See, for example, Pryor (2005b) and Huemer (2007).
} 
A final disanalogy to notice is that perceivers are not subject to epistemic criticism with respect to their perceptual judgments, in the way that Scooter is with respect to his judgments about hypothetical cases. It does not make sense to request that a perceiver give her reasons or justification for her perceptual judgment that there is a red square; she is not expected to be able to specify grounds for judging that it is red, or a square, other than simply to say that it looked that way. But it does make sense to request reasons from Scooter. What is it about the scenario that leads him to judge that Searle doesn't understand? Up to a point, at least, such questions are sensible, and the inability to provide answers can lead us to retract our initial evaluation of the judgment as epistemically appropriate. ${ }^{17}$

So far the cases have a rather a priori or armchair flavor. The third case involves hypothetical reasoning that starts from a realistic but non-actual scenario-a scenario that deviates from the actual world in only minimal ways-and uses a capacity for mental simulation in order to decide how to act in the actual environment.

Case 3: Visualization. While recovering from his most recent humancannonball injury, Gonzo reflects on what he can do differently next time. He asks himself, if the stage lighting rigs had been a bit higher, would I have landed in the net? He constructs a visual "mental model" of the stage, the cannon, and so on, and visualizes the lighting rigs being noticeably higher than they actually were. Gonzo then pictures himself being fired out of the cannon and observes his trajectory. In the scenario as he visualizes it, he lands safely in the net, rather than crashing into the lights. He concludes that yes, if the lighting rigs had been higher then he would have landed in the net.

The acrobatic struggles of the actual Gonzo might lead one to doubt whether he is really competent to make this judgment. But most normal subjects exhibit a capacity for visual mental simulation that is at least good enough for them to solve everyday problems that are similar in kind to the problem Gonzo faces. An ordinary subject can tell, for instance, whether a certain piece of furniture would fit into a particular space by visualizing putting it there. One can tell, by visualizing, whether a particular rock set into motion would roll into the lake if a bush did not occupy a specific location on the slope of hill, to borrow an example from Timothy Williamson. ${ }^{18}$ If Gonzo's capacity for visual mental simulation is reasonably good, then, his belief in the conclusion is justified. It gives him good reason to believe that he should raise the lighting rigs before the upcoming show, for example.

What makes him justified? Gonzo starts his reasoning process with a visual image of the stage comprising the cannon, himself in the cannon, the safety net and the lighting rigs. ${ }^{19}$ This requires him to have some justified beliefs (or at least justification for beliefs) about where things were, how they were arranged, what

\footnotetext{
${ }^{17}$ For a much more thorough discussion of intuitions as inferential responses to hypothetical scenarios see Balcerak Jackson (manuscript).

18 See Williamson (2007, Chap. 5).

19 Let us put aside the question of whether Gonzo imagines this from a first-person perspective of somebody sitting in the cannon waiting to be shot out, or from a third-person perspective looking at himself in the cannon. Nothing here hangs on these two ways to set up the visual mental model.
} 
they looked like, and so on. Perhaps he relies on perceptual memories of the stage in its current set-up, and then modifies this visual image to suit the purpose of his inquiry. Gonzo's visualization is in many ways similar to a genuine perception of the same visual scene..$^{20}$ Because of this, Gonzo might also have some justification concerning how things would look if they were arranged in the way he is imagining. This is all empirical justification that Gonzo brings to the case. But by itself, this justification is not sufficient to fully account for his justification for the conclusion about where he would land. He also needs to have a reasonable basis for making the specific prediction that he does about where he would end up, were he to be shot out of the cannon under the conditions he (justifiably) believes would obtain in the imagined scenario.

As the case is described, Gonzo arrives at such a prediction by visualizing how things would unfold over time, given the initial set-up. That is, he has to construct something like a 'mental movie' that depicts him being shot out of the cannon, flying in a certain trajectory and landing in the net. It is the fact that he adequately constructs and runs such a mental movie, and that it shows him landing in the net, that provides the additional justification needed for him to believe that if the lighting rigs were higher then he would land in the net. Timothy Williamson suggests something similar when he proposes that we evaluate a counterfactual conditional by "developing" its antecedent in certain ways via mental simulation, and then check to see if the consequent is true in the simulation. ${ }^{21}$ Being able to develop the antecedent via mental simulation does not depend on, our amount to, having justification for a theory of from which Gonzo can infer the behavior of physical objects. In Gonzo's case, it is the application of his capacity to develop antecedents via visualization that generates the missing justification for his belief.

Gonzo's mental movie will not issue in a reasonable prediction about what would actually happen to him unless the visualization exercise is appropriately constrained by background information about Gonzo's actual environment. As already noted, this includes constraints imposed by his knowledge of the stage set-up and so on. But one might object that it must surely also include justified beliefs about the possible trajectories of moving objects, approximate laws of nature, and so on. If Gonzo has this then it suffices to fully explain his justification for his belief in the conclusion, and so we do not need to see Gonzo's reasoning itself as contributing any justification.

There are two things to be said in response. First, as was noted in the discussion of Fozzy's deductive reasoning, the objection must be intended quite generally. It must be that every case in which a subject grounds belief in some conclusion via mental simulation, in the way that Gonzo does, the full support for the conclusion is ultimately due to a body of justified background beliefs. Given the extraordinarily

\footnotetext{
${ }^{20}$ It will plausibly share core aspects of the content and phenomenal character with the corresponding perceptual state. But when one engages in voluntary imaginative projects like the one described, one is rarely in danger of confusing imagination with perception. So there must also be representational and/or phenomenal differences that allow one to distinguish the visualization and the corresponding perception.

21 See Williamson (2007, Chap. 5).
} 
diverse range of ways in which visualization and other forms of mental simulation can be employed, this is an implausibly strong claim to make. ${ }^{22}$

Second, the best philosophical and empirical views suggest that our capacity for mental simulation simply cannot be fully explained by our use of background beliefs. $^{23}$ The capacity for visualization is rather tightly connected to our perceptual capacities, as something like an ability to run those capacities off-line. Those, in turn, are formed and shaped by sustained causal interaction with the environment. In this way our capacity for visualization becomes attuned to features of how the environment actually works in ways that are poorly modeled by supposing that it draws on implicit background theories. In order to know how objects will or would move through space, Gonzo can at least sometimes simply rely on this capacity.

If this is so, however, then one might wonder whether we really should count Gonzo's visualization as a case of reasoning. Shouldn't we think of it as being more like the case of basing a belief on perception? ${ }^{24}$ We don't think so. As already noted, Gonzo's case does exhibit the content gap that is the hallmark of cases of genuine reasoning. Moreover, it is appropriate to subject the steps by means of which Gonzo bridges that gap to epistemic appraisal and criticism. If Gonzo allows optimism or ambition to influence his conclusion, for example, we can fairly criticize him for not conducting the simulation as he ought to. It would be no defense for him to insist that this is simply how things look to him when he visualizes the scenario.

\section{Epistemic requirements and cognitive capacities}

We have argued that in each of the cases discussed, the subject's reasoning itself generates at least some of his justification for the conclusion. We have tried to anticipate some of the objections most likely to arise. Still, one might have the sense that something must have gone wrong: our diagnosis might make it seem like these are cases in which the subject somehow gets something for nothing, epistemically speaking, and this surely cannot be a legitimate view of the matter. Perhaps the best way to help assuage this worry is to offer at least the beginnings of a positive epistemological account that helps explain how it can come about that reasoning generates justification.

The account we find most promising begins with the following basic idea. Each of the cases discussed is an instance of what we might call suppositional reasoning:

\footnotetext{
${ }^{22}$ Williamson (2007, Chap. 5) notes that the "folk theories" that allegedly underwrite these sorts of mental simulation very often include principles that are literally false. If so then the beliefs grounded by mental simulation, on the present suggestion, would not qualify as knowledge, even when they are true and justified. This is a further unwelcome result.

23 There is an analogy here with the observation, in the philosophy of science, that even very welldeveloped, successful scientific theories do not eliminate the use of scientific models in order to answer complex questions and make reliable predictions. One can find out where to erect barriers in the San Francisco Bay with minimal risk for the environment by building a model of the bay and putting it to work, even if one is not in a position to find the solution on the basis of physical and technical background knowledge. See Godfrey-Smith (2006, 2009), and for the example Weisberg (2012).

24 Thanks to Miriam Schoenfield for discussion here.
} 
the subject begins by supposing (or imagining or picturing) that a certain proposition is the case, and then proceeds to make some further judgment or judgments, before discharging the supposition and arriving at a flat-out belief. It is the suppositional nature of the reasoning that accounts for the fact that the conclusion reached in each case is conditional in form-that it is a belief that some proposition is (or would or might be) the case if the supposed proposition is (or were) the case. Since the process is one of suppositional reasoning - as opposed to say, mere daydreaming - the transitions from each step to the next are properly held to certain standards of epistemic appropriateness. In the cases we have described, the subjects intuitively live up to those standards, and this is why the beliefs they reach are ultimately justified. It is epistemically appropriate for the subject to believe the conclusion, because it is one he has arrived at on the basis of epistemically appropriate reasoning; the positive epistemic normative status of the reasoning process itself attaches to the belief arrived at by its means. In this sense, they are not cases of getting something for nothing after all.

We can say more about the epistemic standards to which suppositional reasoning is properly held with the help of John Broome's notion of a normative requirement between beliefs. For Broome, normative requirements constitute a parameter of epistemic evaluation that is distinct from that of reasons. ${ }^{25}$ Suppose that Kermit believes that there is a red chair at his desk. The proposition that there is a red chair entails the proposition that there is a chair, but believing the former proposition does not, by itself, give him any justification for believing the latter. After all, it might be that he ought not to believe that there is a red chair in the first place. The relation between the two beliefs is not the relation of being-a-reason-for. Rather, Kermit's belief that there is a red chair normatively requires him to believe that there is a chair: he ought to see to it that if he holds the former belief then he also holds the latter. Kermit can satisfy this requirement either by adopting the belief that there is a chair, or by giving up the belief that there is a red chair. So he and his beliefs can score well along this parameter of epistemic evaluation even if they score badly along the parameter of reasons, and even if he ends up with ultimately unjustified beliefs.

Normative requirements are what matter for the epistemic assessment of a subject's reasoning; to reason appropriately is to live up to one's normative requirements. If all reasoning consisted solely of sequences of beliefs, we could say that a subject reasons appropriately just in case each belief in the sequence is normatively required by the ones before it. ${ }^{26}$ However, the cases we are interested in include sequences of suppositions, and there is little sense to be made of the suggestion that supposing $p$ can require one to suppose $q$. Even if $q$ is an immediate logical consequence of $p$, one may have no interest in $q$ and may blamelessly draw out other consequences of $p$ instead. But normative requirements between beliefs have a mirror image in what we might call relations of normative permission between suppositions: if believing $p$ requires one to believe $q$, then given that one

\footnotetext{
25 Broome (1999).

26 This is essentially Broome's standard; cf. Broome (1999, p. 406).
} 
supposes $p$, one is within one's rights to add $q$ to one's suppositions. ${ }^{27}$ For example, believing that Kermit is a talking green creature plausibly requires the belief that there is at least one talking green creature, and so Fozzy's supposition of the former proposition permits him to add the latter proposition. Good sequences of suppositional reasoning are those in which every suppositional state (after the initial one) is permitted by those before it.

Our view of the cases with which we began, then, is that they are cases in which the subject's belief in the conclusion inherits some justification simply because it is based on a process of suppositional reasoning that lives up to the normative requirements on belief. This is unusual. In typical cases of reasoning, living up to the normative requirements on belief is not enough: the subject must also have sufficient justification for the beliefs that ultimately normatively require the belief in the conclusion, because being required to believe $p$ by one's beliefs does not itself imply having any justification for believing $p$. This is what makes our cases special: the suppositional reasoning involved allows the subject to transform normative requirements into justification.

It will be noted that our account relies on certain presuppositions about what normative requirements exist between beliefs. For example, it presupposes that Fozzy's believing that Kermit is a talking green creature normatively requires him to believe that there is at least one talking green creature. This is surely quite plausible. But it also presupposes that Scooter's believing that Searle is in the Chinese Room requires him to believe that Searle doesn't understand Chinese, and that Gonzo's believing that the cannon is tilted a certain way requires him to believe that he will have a certain trajectory when fired out of it. Can there really be such requirements?

It is plausible that there can be, understood in the right way. In each of the cases discussed, the subject relies on some specific cognitive competence in making the suppositional transitions that are at the core of his reasoning. In Case 1, Fozzy's transition from his assumption about Kermit to the existentially quantified judgment is an exercise of his competence with simple deduction. In Case 2, Scooter exercises his competence in applying the concept understanding by reflecting on the imagined scenario in order to determine that it is one in which Searle does not understand Chinese. And in Case 3, Gonzo exercises his competence in predicting the physical dynamics of ordinary objects. However, it is a familiar point that the range of things one ought to do can expand or contract according to what one has the capacity to do; a competent swimmer ought to help drowning victims in circumstances where nonswimmers are under no such obligation. Normative requirements must likewise be seen as sensitive to the cognitive capacities of subjects. Given Scooter's skill at applying the concept understanding, he would not be doing what he ought to do if he were to believe that Searle is in the Chinese Room but not that Searle fails to

\footnotetext{
27 There is a sense, of course, in which one is always permitted to suppose whatever one likes. Epistemically speaking, there is never anything that speaks against supposing $p$, because doing so incurs no commitment about how things are. But permission in this sense attaches to single suppositions. The notion of permission we are interested in, like Broome's notion of requirement, is essentially a relational one.
} 
understand Chinese- - he would be failing to properly exercise a competence that he should, in these circumstances.

Importantly, however, having such a competence need not be a matter of having a body of justified beliefs. Gonzo is competent at predicting trajectories, not because he has epistemic access to some theory of "folk physics", but because he is good at visualizations that accurately simulate the behaviors of physical objects under various conditions. Gonzo's past experiences surely contribute to his competence. But they do so by helping to shape his simulation skills, not by contributing justification for beliefs that would allow him to infer trajectories from initial conditions. Similarly, Scooter is competent with the concept understanding because he is good at applying it to actual and hypothetical cases on the basis of various sorts of information about those cases. But he can (and most of us do) acquire this competence without first acquiring justification for believing some theory about what does and does not count as a case of understanding. As for Fozzy, one might maintain that his basic logical competence is something that is constitutive of his status as a reasoner to begin with. If so, this is all the more reason to acknowledge that his competence cannot ultimately depend on him having prior justification for beliefs about what follows from what.

If something along the lines of the account sketched here is correct, then one would expect at least sometimes to encounter cases in which reasoning generates justification. Surely there are some reasoning capacities that work by grounding normative requirements on belief, rather than by providing reasons for belief. And many reasoning capacities can be put to work to extract the consequences of hypothetical suppositions. We have given three examples here that appear to be good candidates. No doubt there are others.

Acknowledgments In preparing this paper we benefitted enormously from discussions with others. In particular, we are grateful for feedback from participants at the Knowledge in a World of Symbols workshop at the University of Hamburg, from participants at the Bellingham Summer Philosophy Conference, and from members of the weekly reading group of our project Understanding and the A Priori at the University of Cologne. Thanks especially to Sven Bernecker, Lars Dänzer, Blake Roeber and Miriam Schoenfield for their thoughtful comments. The research for this paper was supported by a grant from the German Research Council (Deutsche Forschungsgemeinschaft).

\section{References}

Balcerak Jackson, M. (2012). Conceptual analysis and epistemic progress. Synthese. doi: 10.1007/s11229-012-0120-0.

Balcerak Jackson, M. (Manuscript). Intuitions as inferential judgments.

Bengson, J. (Manuscript). The intellectual given.

Boghossian, P. (2003). Blind reasoning. Aristotelian Society Supplementary Volume, 77, 225-248.

Broome, J. (1999). Normative requirements. Ratio, 12, 398-419.

Broome, J. (2001). Normative practical reasoning. Aristotelian Society Supplementary Volume, 75, $175-193$.

Carroll, L. (1895). What the tortoise said to Achilles. Mind, 4, 278-280.

Chudnoff, E. (2011). The nature of intuitive justification. Philosophical Studies, 153, 313-333.

Godfrey-Smith, P. (2006). The strategy of model-based science. Biology and Philosophy, 21, 725-740.

Godfrey-Smith, P. (2009). Models and fictions in science. Philosophical Studies, 143, 101-116.

Huemer, M. (2007). Compassionate phenomenal conservatism. Philosophy and Phenomenological Research, 74, 30-55. 
Pryor, J. (2005a). There is immediate justification. In M. Steup \& E. Sosa (Eds.), Contemporary debates in epistemology. Oxford: Blackwell.

Pryor, James. (2005b). The skeptic and the dogmatist. Noûs, 34, 517-549.

Searle, J. R. (1980). Minds, brains, and programs. Behavioral and Brain Sciences, 1, 417-424.

Weisberg, M. (2012). Simulation and similarity. Using models to understand the world. Oxford.

Williamson, T. (2007). The philosophy of philosophy. Oxford: Blackwell. 